\title{
Estudios de Caracterización Cinética y Fisicoquímica de una Proteinasa Aspártica Aislada de Frutos Maduros de Salpichroa origanifolia
}

\author{
Gabriela F. Rocha, Graciela Fernández y Mónica G. Parisi * \\ Universidad Nacional de Luján, Departamento de Ciencias Básicas, C.C. 221, Ruta 5 y Avenida
} Constitución, (6700) Luján, Buenos Aires-Argentina (e-mail: mgp@mail.unlu.edu.ar)

*Autor a quien dirigir la correspondencia

\begin{abstract}
Resumen
Una nueva enzima proteolítica con actividad coagulante de la leche fue aislada de frutos maduros de Salpichroa origanifolia. El extracto crudo se obtuvo disolviendo el polvo etanólico de los frutos maduros en $50 \mathrm{mM}$ de buffer de fosfatos de $\mathrm{pH}$ 7.0. La enzima presentó actividad proteolítica frente a sustratos proteicos como hemoglobina y caseína. La hidrólisis de estos sustratos fue óptima en un rango de $\mathrm{pH}$ entre 3.5 y 6.5 a temperaturas entre 40 y $45^{\circ} \mathrm{C}$. Se observó también que los extractos enzimáticos eran muy estables a temperaturas moderadas $\left(40^{\circ} \mathrm{C}\right)$ y que la actividad enzimática era incrementada por cationes como calcio y magnesio. Cuando se estudió la degradación in vitro de la caseína bovina por acción del extracto crudo se observó que la enzima vegetal producía un mayor grado de hidrólisis que el cuajo comercial. De los resultados obtenidos se concluye que la proteinasa aspártica aislada de Salpichroa origanifolia presenta actividad coagulante de la leche y características de termoestabilidad adecuadas para su empleo en procesos biotecnológicos.
\end{abstract}

\section{Kinetic and Physicochemical Studies of an Aspartic Proteinase Isolated from Salpichroa origanifolia Fruits}

\begin{abstract}
A new proteolytic enzyme with milk-clotting activity was isolated from ripe fruits of Salpichroa origanifolia. Crude extract was obtained by dissolving the ethanolic powder of the fruits in $50 \mathrm{mM}$ phosphate buffer $\mathrm{pH}$ 7.0. The enzyme presented proteolytic activity toward denatured protein substrates. Hemoglobin and casein hydrolysis were optimal in the $\mathrm{pH}$ range 3.5 to 6.5 at temperatures between 40 and $45^{\circ} \mathrm{C}$. In addition, the crude extract showed high stability at moderate temperatures $\left(40^{\circ} \mathrm{C}\right)$ and the proteinase activity was activated by cations such as calcium and magnesium. Degradation pattern of the bovine casein brought about by the crude extract of Salpichroa origanifolia produced higher hydrolysis degree than the commercial rennet. According to these results, it is concluded that the aspartic proteinase isolated from ripe fruits of Salpichroa origanifolia presents appropriate milk-clotting activity and thermostability properties for its use in biotechnological processes.
\end{abstract}

Keywords: aspartic proteinase, milk-clotting activity, kinetic characterization, proteolytic enzyme, Salpichroa origanifolia. 


\section{INTRODUCCIÓN}

Las peptidasas aspárticas (APs) están ampliamente distribuidas en la naturaleza (vertebrados, hongos, plantas, protozoos y en retrovirus) y se caracterizan por ser activas a pH ácido (Rawlings y Barrett, 2004). En plantas, se han aislado en monocotiledóneas, dicotiledóneas y gimnospermas. La función biológica que cumplen en ellas no está totalmente caracterizada como sucede en los mamíferos, sin embargo se ha encontrado que las APs de plantas superiores participan en procesos fisiológicos, entre ellos en la senescencia foliar, en la muerte celular programada, en la reproducción, en respuesta al stress biótico o abiótico y en los mecanismos de defensa frente a patógenos (Duarte et al., 2008).

El uso de enzimas proteolíticas es altamente relevante en biotecnología, especialmente en la producción de hidrolizados de proteínas (Vairo Cavalli et al., 2008; Ubalde y Cantera, 2002) y en la elaboración de quesos (Prados et al., 2007). El cuajo obtenido del cuarto estómago del ternero ha sido usado tradicionalmente como coagulante en muchas industrias de quesos ya que hidroliza el enlace Phe105-Met106 de la kappa-caseína en forma rápida y específica. Sin embargo, el aumento del consumo de queso y la disminución en el faenamiento de terneros condujo a un aumento del precio del cuajo que se tradujo en una búsqueda de coagulantes alternativos de origen microbiano, animal (pepsina de pollo, cerdo, cabrito, ovinos, etc.) y de plantas. Estas últimas han sido empleadas en la elaboración de quesos artesanales en Portugal, España, Francia e Italia (Silva y Malcata, 2004). En la actualidad el sustituto utilizado y con muy buenos resultados es el cuajo obtenido por ingeniería genética (Claverie-Martín y Vega-Hernández, 2007).

La especie Salpichroa origanifolia es una hierba perenne, autóctona del Norte y Centro de Argentina, Uruguay y Brasil. Sus frutos, en forma de baya ovoide y comúnmente llamados "huevitos de gallo", han sido empleados en medicina popular por sus propiedades farmacológicas (Bado et al., 2004). En trabajos previos realizados en el laboratorio de Química Biológica del Departamento de Ciencias Básicas de la Universidad Nacional de Luján ha sido aislada y purificada una proteinasa aspártica con actividad coagulante de la leche a partir de frutos maduros de Salpichroa origanifolia.

En este trabajo se realiza la caracterización cinética de la enzima aislada empleando hemoglobina y caseína como sustratos proteicos naturales, así como la determinación de los parámetros fisicoquímicos de importancia para su posible empleo biotecnológico.

\section{MATERIALES Y MÉTODOS}

Como material vegetal de estudio se emplearon los frutos maduros de Salpichroa origanifolia. La recolección de los frutos se realizó a partir de plantas crecidas en la localidad de Luján, provincia de Buenos Aires, República Argentina.

Para la preparación del extracto crudo, los frutos se trituraron con etanol a $-8^{\circ} \mathrm{C}$. El precipitado se resuspendió en $50 \mathrm{mM}$ de buffer fosfato de $\mathrm{pH} 7.0\left(\mathrm{a} 4{ }^{\circ} \mathrm{C}\right)$ y se obtuvo un extracto al $15 \%(\mathrm{p} / \mathrm{V})$. A esta preparación enzimática se la denominó extracto crudo. La determinación de la actividad proteolítica fue realizada utilizando hemoglobina al $2 \%(\mathrm{p} / \mathrm{V})$ como sustrato proteico de acuerdo al método de Anson con algunas modificaciones (Anson, 1938). Para realizar el ensayo, se incubaron $200 \mu \mathrm{L}$ del extracto crudo con $4 \mu \mathrm{L}$ de una solución de $\mathrm{CaCl} 2(1 \mathrm{M})$ a $40^{\circ} \mathrm{C}$ y luego de 5 minutos se agregaron $200 \mu \mathrm{L}$ de solución de hemoglobina desnaturalizada al $2 \%(\mathrm{p} / \mathrm{V})(\mathrm{pH}: 3.50)$. Luego de 10 minutos de incubación, la reacción se detuvo con la adición de $700 \mu \mathrm{L}$ de TCA al 5\% (p/V), se mantuvo en reposo durante 20 minutos en baño de hielo y luego se centrifugó a 14,000 rpm durante 5 minutos. Sobre $0.5 \mathrm{~mL}$ del sobrenadante se adicionaron $0.3 \mathrm{~mL}$ de reactivo de Folin y se leyó la absorbancia de la solución resultante a $750 \mathrm{~nm}$ en un espectrofotómetro Hitachi U-2000.

La unidad de actividad enzimática fue definida como la cantidad de enzima requerida para lograr un incremento de una unidad en la absorbancia por minuto a $750 \mathrm{~nm}$ en las condiciones del ensayo (10 minutos y $40^{\circ} \mathrm{C}$ ). Los ensayos de coagulación se realizaron de acuerdo a normas FIL (IDF Standard 157A: 1997). El extracto vegetal se comparó con un cuajo genéticamente modificado, denominado FPC. 
La concentración de proteínas fue estimada por el método de Bradford (1976) empleando albúmina sérica bovina como estándar para la construcción de la curva de calibración.

\section{Caracterización fisicoquímica y cinética de la enzima}

Efecto del $\mathrm{pH}$ sobre la actividad enzimática: Para estudiar el efecto del pH sobre la actividad proteolítica de la enzima se emplearon soluciones buffer en un rango de $\mathrm{pH}$ comprendido entre $2.0 \mathrm{y}$ 6.0

Efecto de la temperatura sobre la actividad enzimática: El comportamiento enzimático a distintas temperaturas se determinó midiendo la actividad proteolítica frente a hemoglobina $(\mathrm{a} \mathrm{pH:} \mathrm{3.5)} \mathrm{en} \mathrm{un}$ rango de temperaturas comprendido entre $20-55^{\circ} \mathrm{C}$ y a intervalos de $5^{\circ} \mathrm{C}$.

Estabilidad térmica: Para realizar los estudios de estabilidad térmica de la enzima, se incubaron muestras de extracto crudo durante $15,30,45,60,90,105$ y 120 minutos a 40, 45, 50 y $55{ }^{\circ} \mathrm{C}$. Luego de cada tratamiento las muestras fueron conservadas en baño de hielo hasta el momento de la determinación de la actividad.

Efecto de cationes metálicos: Se estudió el efecto de cationes divalentes como el calcio y el magnesio en distintas concentraciones (10, 50 y $100 \mathrm{mM})$ sobre la actividad enzimática de los extractos crudos. La medición de la actividad proteolítica se realizó de acuerdo a la técnica detallada empleando hemoglobina al $2 \%(p / V)$ como sustrato proteico.

Cinética de degradación de la caseína bovina: Se estudió el grado de hidrólisis producido por el extracto crudo de la enzima sobre la caseína bovina y se comparó con la producida con el cuajo comercial (FPC). La actividad caseinolítica fue medida empleando caseína al 1\% (p/V) como sustrato proteico. Para estudiar la degradación del sustrato en el tiempo, se incubaron $3 \mathrm{~mL}$ del sustrato con $120 \mu \mathrm{L}$ de cada extracto enzimático a $37^{\circ} \mathrm{C}$ y se tomaron alícuotas en distintos tiempos de incubación. La reacción se detuvo con el agregado de $1 \mathrm{~mL}$ de TCA al 5\% (p/V) y se cuantificaron espectrofotométricamente $(280 \mathrm{~nm})$ los péptidos solubles en TCA.

Electroforesis en geles de poliacrilamida: Los productos de hidrólisis fueron caracterizados por electroforesis UREA-PAGE en un equipo Bio-Rad Miniprotean III. Para la preparación de las muestras se incubaron durante 30 minutos, $100 \mu \mathrm{L}$ de extracto crudo con $1 \mathrm{~mL}$ de leche descremada en polvo $(12 \% \mathrm{p} / \mathrm{V})$ reconstituida en una solución $20 \mathrm{mM}$ de $\mathrm{CaCl}_{2}$. El precipitado obtenido se separó por centrifugación (5000 rpm y 10 minutos) y se lavó con agua. Se redisolvió en buffer de muestra (1\% $\beta$ - mercaptoetanol, glicerol, azul de Bromofenol, buffer Tris- $\mathrm{HCl}$ y $9 \mathrm{M}$ de urea).

Las muestras testigos utilizadas en el ensayo fueron las fracciones $\alpha$ y $\beta$ de la caseína obtenidas a partir de la precipitación de la leche cruda con $\mathrm{HCl} 6 \mathrm{M}$. El precipitado obtenido se resuspendió en una solución $9 \mathrm{M}$ de urea con $\beta$-mercaptoetanol al 1\% y se llevó a pH 7,0 con $\mathrm{NaOH}(1 \mathrm{~N})$. Se sembraron $15 \mu \mathrm{L}$ de las muestras en los geles verticales y se utilizó buffer TRIS-glicina $\mathrm{pH} 8,9$. La corrida electroforética se desarrolló durante 90 min a $30 \mathrm{~mA} / \mathrm{gel}$. Las proteínas se colorearon con Coomasie Blue R-250 (Vairo Cavalli et al., 2008)

Determinación de las constantes cinéticas: Sobre la fracción activa y purificada por intercambio iónico, denominada SoAP, se estudiaron las constantes cinéticas empleando hemoglobina como sustrato proteico. A partir de las determinaciones de velocidad inicial $\left(\mathrm{V}_{0}\right)$ llevadas a cabo utilizando seis concentraciones de sustrato se estimaron la $\mathrm{Km}$ y la Vmáx. Las pendientes y ordenadas al origen se obtuvieron mediante análisis de regresión lineal a partir de los gráficos de las dobles recíprocas de Lineweaver- Burk. Los experimentos se realizaron por triplicado.

Cinética de inhibición con Pepstatina: Para determinar la concentración del sitio catalítico de la enzima, se estudió la cinética de inactivación con Pepstatina, inhibidor específico de las peptidasas aspárticas (Knight, 1999). En los experimentos se incubaron $200 \mu \mathrm{L}$ de la enzima con $2 \mu \mathrm{L}$ de distintas concentraciones de Pepstatina $(0-1 \mu \mathrm{M})$ durante 30 min a $30^{\circ} \mathrm{C}$ y se determinó luego la actividad residual con hemoglobina $a 0^{\circ} \mathrm{C}$. 


\section{RESULTADOS Y DISCUSIÓN}

En ensayos previos realizados en nuestro laboratorio se encontró que el extracto crudo obtenido a partir de frutos maduros de Salpichroa origanifolia presentaba actividad proteolítica y poder coagulante de la leche (Tabla 1). Este extracto enzimático fue empleado en la elaboración de quesos de pasta blanda (Rocha et al., 2006)

Tabla 1: Comparación de la actividad proteolítica y el poder coagulante en frutos verdes y maduros de Salpichroa origanifolia

\begin{tabular}{ccc}
\hline $\begin{array}{c}\text { Estadío de } \\
\text { maduración del fruto }\end{array}$ & $\begin{array}{c}\text { Actividad específica } \\
(\mathrm{AE})\end{array}$ & $\begin{array}{c}\text { Tiempo de } \\
\text { coagulación de la } \\
\text { leche (min) }\end{array}$ \\
\hline $\begin{array}{c}\text { Fruto verde } \\
\text { (inmaduro) }\end{array}$ & $272 \mathrm{UHem} / \mathrm{mg}$ & No coagula \\
Fruto maduro & 270 Uhem/mg & 40 \\
\hline
\end{tabular}

\section{Caracterización fisicoquímica de la enzima}

Como la pureza de una enzima no es un factor limitante para su uso industrial (Illanes, 1994), los ensayos de caracterización se realizaron sobre los extractos crudos obtenidos por precipitación etanólica en frío $\left(\mathrm{a}-20^{\circ} \mathrm{C}\right)$. Este procedimiento inicial permitió obtener un extracto crudo con menor contenido de carbohidratos solubles y compuestos fenólicos que pudieran oxidar o afectar irreversiblemente el sitio catalítico de la enzima. El precipitado etanólico redisuelto en buffer contenía un $10 \%$ más de proteínas y mayor actividad específica (272 UHem/mg) que el homogenato obtenido por trituración directa de los frutos en el buffer (123 UHem/mg).

Con el objeto de analizar la posible aplicación biotecnológica de la enzima, se estudiaron los parámetros bioquímicos que afectan la actividad enzimática. Se encontró que la enzima era activa a $\mathrm{pH}$ ácido con un óptimo valor a $\mathrm{pH} 3.5$ (Fig. 1) y que los cationes $\mathrm{Ca}^{* 2}$ y $\mathrm{Mg}^{+2}$ producían un incremento de la actividad enzimática (Fig. 2).

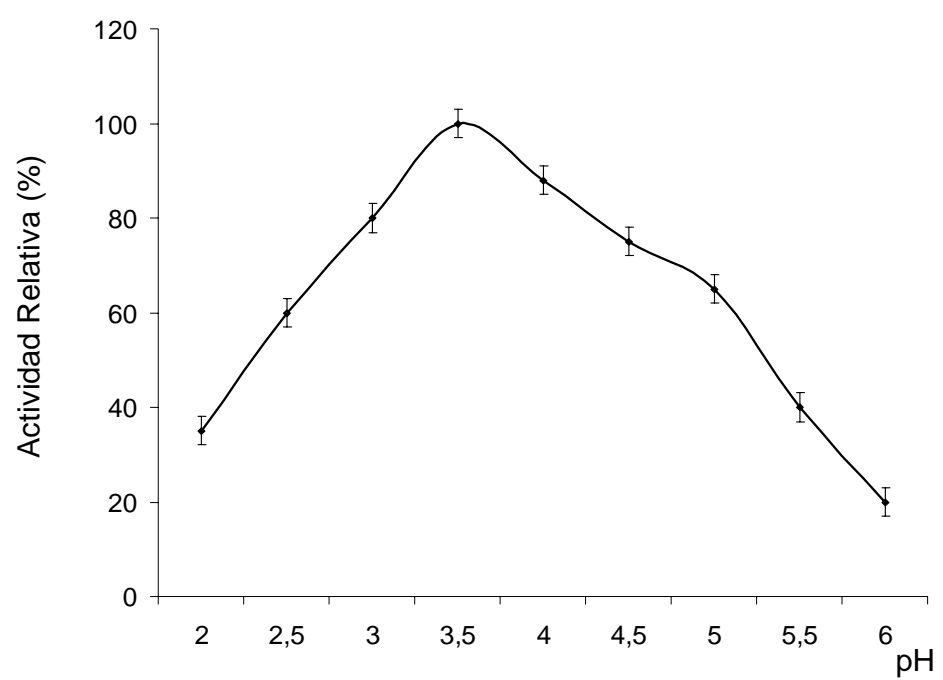

Fig. 1: Variación de la actividad proteolítica del extracto crudo en función del pH. Se realizaron 2 ensayos independientes y las muestras se procesaron por triplicado. 


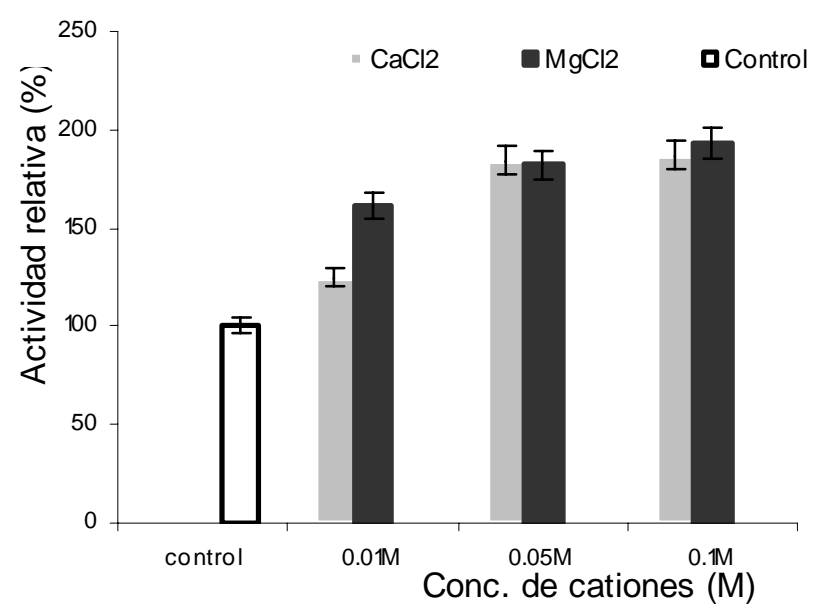

Fig. 2: Efecto de cationes (calcio y magnesio) sobre la actividad proteolítica del extracto crudo

Al evaluar el efecto de la temperatura sobre el extracto crudo se encontró que la actividad enzimática era óptima en un rango de temperaturas entre $40-45^{\circ} \mathrm{C}$ (Fig. 3).

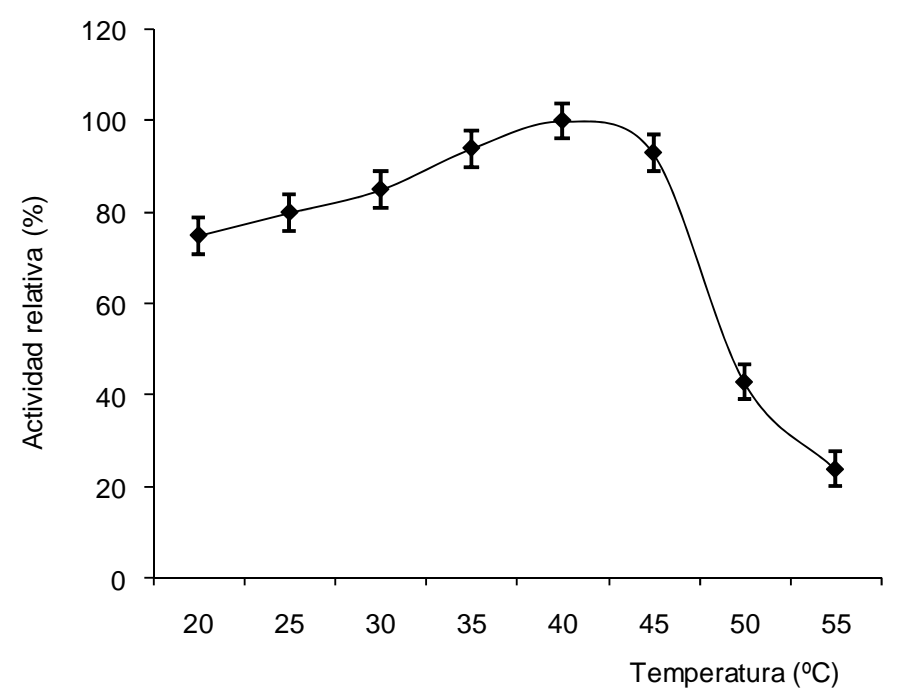

Fig. 3: Efecto de la temperatura sobre la actividad proteolítica del extracto crudo. Los valores expresados para cada temperatura representan el promedio de 3 mediciones independientes.

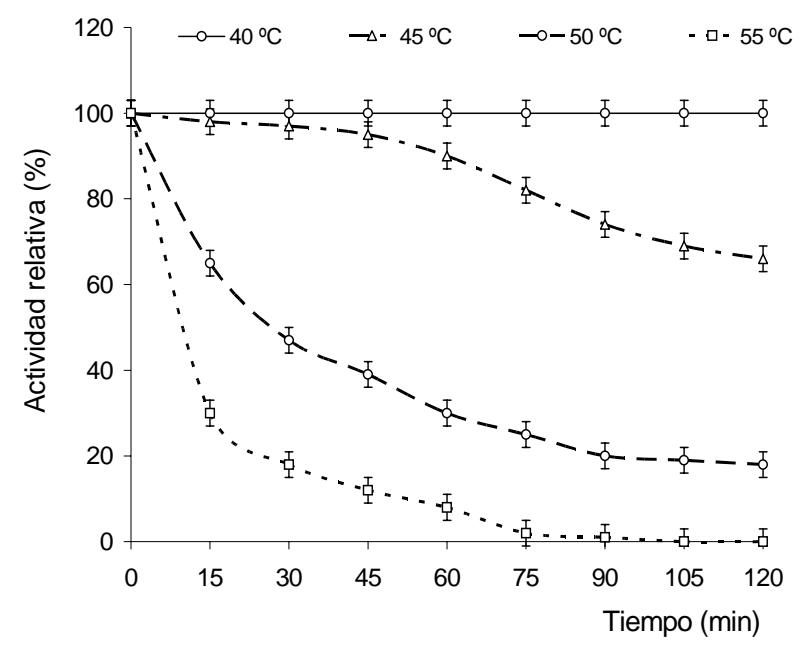

Fig. 4: Estabilidad térmica del extracto crudo en el tiempo. Los datos surgen de promediar 2 experimentos independientes realizados por triplicado. 
Se estudió luego la estabilidad de la enzima en el rango de temperatura óptima y se observó que la enzima podía ser empleada con escasa pérdida de actividad durante 2 a 3 horas por debajo de $45^{\circ} \mathrm{C}$, y en procesos breves (10 - 15 minutos) a mayores temperaturas, entre $50-55^{\circ} \mathrm{C}$ (Fig. 4).

Estas características de estabilidad son sumamente ventajosas para el empleo de la enzima en procesos industriales ya que, podría ser utilizada en un rango de temperaturas moderadas durante 3 horas sin pérdidas apreciables de su actividad biológica.

\section{Caracterización cinética de la enzima}

Teniendo en cuenta el posible empleo de la enzima en la elaboración de quesos o en la producción de hidrolizados de proteínas, se estudió in vitro la cinética de degradación de la caseína bovina por acción del extracto crudo y se encontró que el cuajo vegetal producía un mayor grado de hidrólisis de la caseína que el cuajo recombinante FPC (Fig. 5 A).
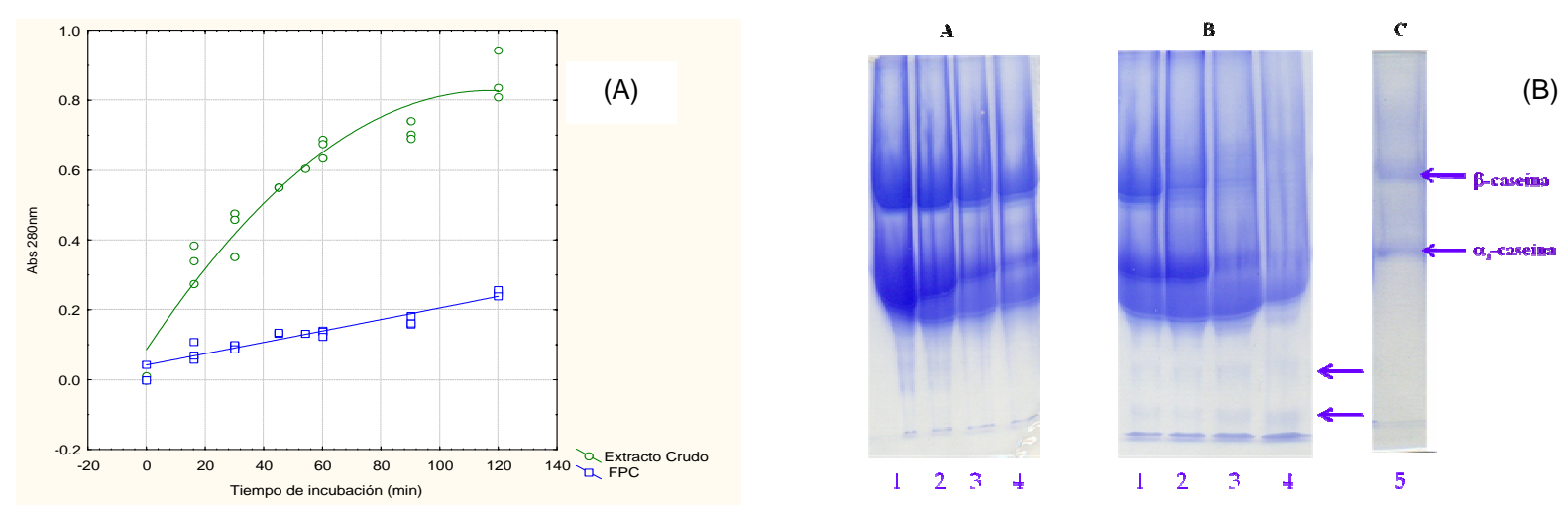

Fig. 5: (A) Variación de la actividad proteolítica en función del tiempo; (B): Electroforesis UREAPAGE. Perfil de hidrólisis de la caseína bovina por acción del FPC (A) y del EC (B) durante 1, 2, 3 y 6 horas de incubación (calles $1,2,3$ y 4 respectivamente). Calle $5, \alpha_{s}$-caseína y $\beta$-caseína obtenidas a partir de leche cruda.

Se analizaron por electroforesis UREA-PAGE los perfiles de hidrólisis del sustrato en el tiempo y se los comparó con los obtenidos por la enzima FPC. Se encontró que la fracción $\beta$ de la caseína era degradada por el extracto crudo luego de 3 horas de incubación, en tanto que la fracción $\alpha_{s}$-caseína era gradual y parcialmente degradada durante 6 horas de hidrólisis produciendo péptidos de bajo peso molecular (Fig. 5 B). Luego se estudiaron las constantes cinéticas utilizando hemoglobina como sustrato. Para ello el extracto crudo fue purificado a homogeneidad.

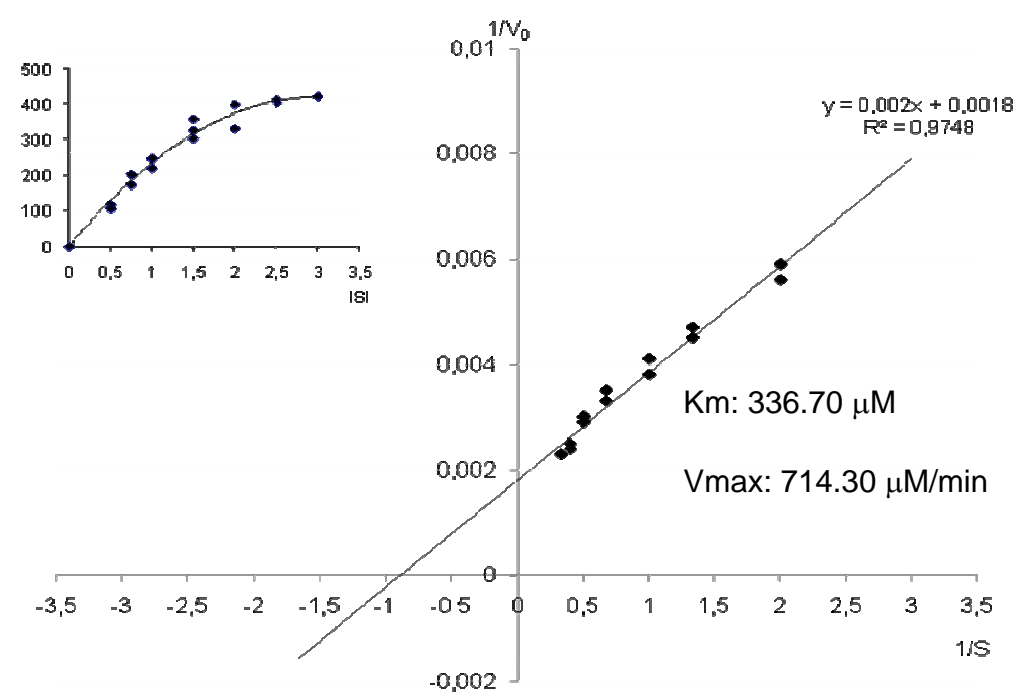

Fig. 6: Efecto de la concentración de sustrato (hemoglobina) sobre la velocidad inicial de la enzima 
La estrategia de purificación elegida consistió en una cromatografía de intercambio aniónico en resinas de DEAE-Sepharose Fast Flow (equilibrada en buffer de fosfatos de $\mathrm{pH} 7.0$ y eluída con un gradiente de $\mathrm{NaCl}, 0-0.6 \mathrm{M})$. Las fracciones con actividad proteolítica fueron desaladas por cromatografía de exclusión molecular y la homogeneidad de la enzima fue determinada por SDSPAGE con tinción con plata, zimogramas e isoelectroenfoque. Se encontró una proteína pura, a la cuál denominamos SoAP, de peso molecular aparente de 29 kDa, heterodimérica, que contenía unidades de peso molecular 17 y $9 \mathrm{kDa}$ y con un pl de 5.2 (Parisi et al., 2006). La fracción pura presentaba una cinética de tipo Michaelis-Menten con un valor de $\mathrm{Km}$ : $336.70 \mu \mathrm{M}$ y una Vmáx: $714.30 \mu \mathrm{moles} / \mathrm{min}$ (Fig.6). Se encontró que el valor de Km para esta enzima mostraba una menor afinidad por este sustrato que la APs aislada de semillas de Vigna radiata (Kulkarni y Rao, 2007)

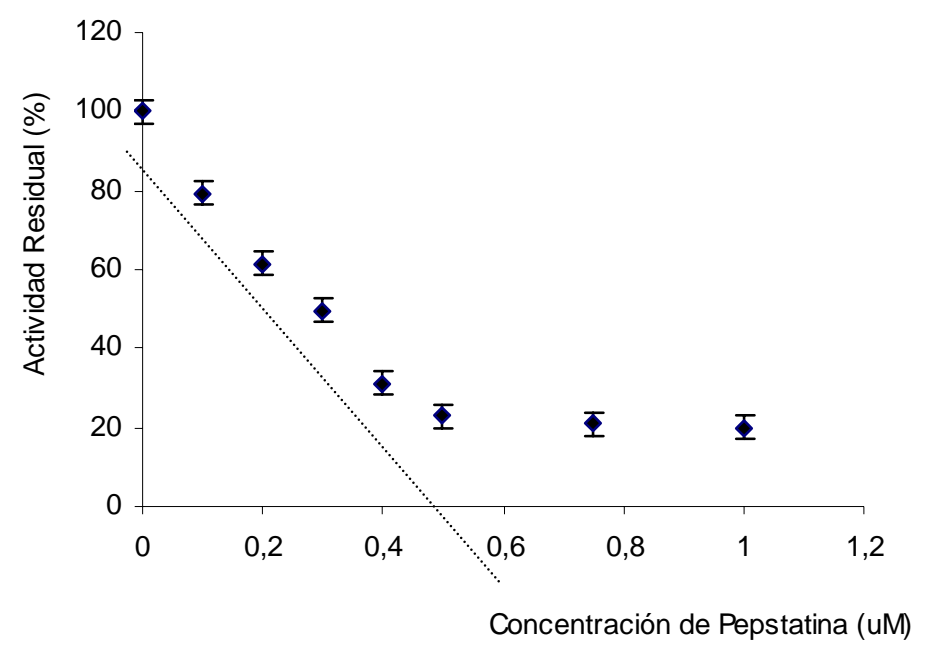

Fig. 7: Titulación del sitio activo de SoAP con Pepstatina

Se determinó la concentración de la enzima activa mediante la titulación del sitio catalítico con Pepstatina, inhibidor específico de las peptidasas aspárticas. El resultado de este ensayo mostró un valor de la concentración del sitio activo aproximadamente $0.6 \mu \mathrm{M}$ (Fig. 7)

\section{CONCLUSIONES}

Una nueva enzima proteolítica con actividad coagulante de la leche fue aislada a partir de frutos maduros de Salpichroa origanifolia. El extracto crudo de la enzima era activo a pH ácido y temperaturas moderadas y la actividad enzimática era incrementada por cationes calcio y magnesio. De acuerdo con los datos bibliográficos, este es el primer reporte donde se describe y caracteriza una proteinasa aspártica constitutiva en frutos, pues hasta el presente sólo se había informado la presencia de estas enzimas en flores, hojas, semillas y tubérculos.

Se han hecho numerosos intentos para reemplazar el cuajo de origen animal, tradicionalmente empleado en la elaboración de quesos, pues en algunos países no está permitido el uso de cuajo animal o recombinante por cuestiones religiosas o biotecnológicas (Vioque et al., 2000; Machalinski et al., 2006). En consecuencia se ha puesto énfasis en estudiar las posibilidades del empleo de enzimas vegetales en estos procesos industriales (Prados et al., 2007).

De acuerdo con los resultados obtenidos en este trabajo se concluye que la proteinasa aspártica aislada de frutos maduros de Salpichroa origanifolia presenta características cinéticas y de termoestabilidad adecuadas para su empleo en procesos biotecnológicos. Actualmente, se están realizando estudios de optimización de los parámetros fisicoquímicos que intervienen en el proceso de elaboración de quesos.

\section{REFERENCIAS}

Anson, L.; The estimation of pepsin, tripsin, papain and cathepsin with hemoglobin, J. Gen. Physiol.: 22, 79-89 (1938). 
Bado, S. y otros cuatro autores; Lethal and sublethal effects of withanolides from Salpichroa origanifolia and analogues on Ceratitis capitata, J. Agric. Food Chem.: 52(10), 2875-2878 (2004).

Bradford, M.; A rapid and sensitive method for the quantitation of microgram quantities of protein utilizing the principle of Protein-Dye Binding, Anal. Biochem.: 72, 248- 254 (1976).

Claverie-Martín, F. y A.M.C. Vega-Hernández; Aspartic proteases used in cheese making, in: Industrial Enzymes by J. Polaina and A.P. Mac Cabe (eds.), Chapter 13, Springer-Verlag Berlin Heidelberg (2007).

Duarte P., J. Pisarra e I. Moore; Processing and trafficking of a single isoform of the aspartic proteinase cardosin A on the vacuolar pathway, Planta: 227, 1225-1268 (2008).

IDF Standard 157A. Bovine rennets. Determination of total milk-clotting activity (1997).

Illanes, A.; Biotecnología de enzimas, Ediciones Universitarias de Valparaíso, Pontificia Universidad Católica de Valparaíso, Secretaría General de la OEA, Programa Regional de Desarrollo Científico y Tecnológico, Serie de Biología, Monografía Nº 35, pp. 45, Chile (1994).

Knight G.; Kinetic Analysis of Protease Inhibition by Synthetic Inhibitors, in: Proteolytic Enzymes Tools and Targest by E.E. Sterchi and W. Stocker (eds), Chapter 11, Springer-Verlag Berlin Heidelberg (1999).

Kulkarni, A. Y M. Rao; Biochemical characterization of an aspartic protease from Vigna radiata: Kinetic interactions with the classical inhibitor pepstatin implicating a tight binding mechanism, Biochem. Biophys. Acta: 1274, 619-627 (2007).

Machalinski, C. y otros cuatro autores; Structural aspects of the Mucor bacilliformis proteinase, a new member of the aspartyl-proteinase family, J. Biotechnol.: 123, 443-452 (2006).

Parisi, M., G. Rocha y G. Fernández; Characterization of a milk clotting peptidase isolated from Salpichroa origanifolia fruits, Biocell, Vol. 30, pp. 243, SAIB, XLII Annual Meeting, Rosario Argentina, 12 al 15 de noviembre (2006), http://www.saib.org.ar/paginas/2006/interiorlibro2006.pdf

Prados, F., A. Pino y J. Fernández-Salguero; Effect of a powdered vegetable coagulant from cardoon Cynara cardunculus in the accelerated ripening of Manchego cheese, Int. J. Food Sci. Technol.: 42, 556-561 (2007).

Rawlings, N.D. y A.J. Barrett; Aspartic peptidases and their clans; in: Handbook of Proteolytic Enzymes by A.J. Barrett, N.D. Rawlings y J.F. Woessner (eds.), Vol 1, pp. 3-12, Elsevier Academic Press, London, England (2004).

Rocha, G., O. López y G. Fernández; Elaboración de quesos de pasta blanda con enzima vegetal de Salpichroa origanifolia (Huevito de gallo), Ciencia Actual: 1(3), 851-857 (2006).

Silva, S. y F. Malcata; Studies pertaining to coagulant and proteolytic activities of plant proteases from Cynara cardunculus, Food Chem.: 89(1), 19-26 (2004).

Ubalde, M.C. y A.M. Cantera; Utilización de una mezcla de proteasas para la obtención de hidrolizados de lactosueros de bajo grado de hidrólisis, Información Tecnológica: 13(5), 77-84 (2002). Vairo Cavalli, S. y otros cuatro autores; Hydrolysis of caprine and ovine milk proteins, brought about by aspartic peptidases from Silybum marianum flowers, Food Chem.: 106, 997-1003 (2008)

Vioque, M. y otros 5 autores; Chemical and microbiological characteristics of ewes'milk cheese manufactured with extracts from flowers of Cynara cardunculus and Cynara humilis as coagulants, $\mathrm{J}$. Agric. Food Chem.: 48, 451-456 (2000). 